\title{
Semaphorin 4D induces an imbalance of Th17/Treg cells by activating the aryl hydrocarbon receptor in ankylosing spodylitis
}

Jianmin Xie ( $\sim$ xiejmdoc@163.com )

Nanjing Medical University Second Affiliated Hospital

Wang Zitao

Nanjing Medical University Second Affiliated Hospital

Gu Jieruo

Third Affiliated Hospital of Sun Yat-Sen University

Research article

Keywords: ankylosing spondylitis; Semaphorin 4D; Th17; Treg; aryl hydrocarbon receptors

Posted Date: March 26th, 2020

DOI: https://doi.org/10.21203/rs.3.rs-18464/v1

License: (c) (i) This work is licensed under a Creative Commons Attribution 4.0 International License.

Read Full License 


\section{Abstract}

Background: Semaphorin 4D (Sema4D) is constitutively expressed on T cells and osteoclasts, and regulates $T$ cell proliferation and bone remodeling. In addition, several studies have shown that Sema4D is involved in the pathogenesis of autoimmunity. We undertook this study to investigate the mechanism by which Sema4D affects the pathogenic progress of ankylosing spondylitis (AS).

Methods: Soluble Sema4D (sSema4D) levels in serum were analyzed by enzyme-linked immunosorbent assay. The cell surface levels and transcripts of Sema4D were evaluated in CD4+ and CD19+ cells from the AS patients and healthy individuals. The mRNA expression levels were assessed by quantitative polymerase chain reaction (qPCR). The proportions of Treg cells and IL-17-producing T-cells (Th17 cells) differentiated from CD4+ T cells were analyzed by flow cytometric analysis. The aryl hydrocarbon receptor (AhR) agonistic effect of Sema4D was detected by analyzing the activation of downstream signaling pathways and target genes using Luciferase and EROD assay.

Results: Levels of sSema4D were elevated in both serum from AS patients, and clinical features markers were correlated with serum sSema4D levels. Sema4D facilitated CD4+ T cells proliferation and Th17 cells differentiation and inhibited Treg cells differentiation by enhancing RORyt expression and reducing Foxp3 expression, with increasing expression and secretion of IL-17 and IL-22. It induced the expression and activity of AhR target gene CYP1A1 and XRE reporter activity via interaction with CD72.

Conclusions: These findings indicate that Sema4D as a potent activator of T cells in the immune response contributes to the inflammation of AS by inducing imbalance in Th17 and Treg cell populations in an AhR-dependent manner, suggesting it is a crucial participant in AS pathogenesis.

\section{Background}

Ankylosing Spondylitis(AS) is a chronic auto-inflammatory rheumatic disease characterized by immunoinflammatory responses and abnormal bone remodeling, such as inflammatory cytokines, syndesmophytes, erosions and osteoporosis, are features of progressive ankylosing spondylitis[1, 2]. Accumulating findings demonstrated that T-helper 17 (Th17) cells as a subgroup of CD4 + T cells, secrete interleukin (IL)-17, enhance pro-inflammatory effects and aggravate AS. Conversely, regulatory T (Treg) cells contribute critically to the protection against pathogenic $T$ cell responses and the maintenance of dominant immune homeostasis[3, 4]. Recent studies indicate that AS is significantly associated with the number of peripheral blood Th17 cells[5]. Growing reports verified that the ratio of Th17 to Treg cells was elevated in AS patients, suggesting that the balance between Th17 and Treg cells may be a crucial factor for AS development $[5,6]$. In addition, it has been showed that inflammatory cytokines, immune cells and osteocytes might be responsible for bone remodeling in AS. The pathophysiology of AS is one of abnormal bone metabolism characterized by pathological bone loss of trabecular bone in the center of the vertebral bodies with new bone formation in the cortical areas of the vertebrae[7, 8]. To date, the exact pathogenesis of immune activation and abnormal bone remodeling in AS remains obscure. In order for 
AS patients to acquire true remission of their disease, it will be indispensable to seek another pivotal molecular player that conduces to immune activation and bone loss in AS.

Accumulating evidence has showed that the aryl hydrocarbon receptor $(A h R)[9,10]$, a ligand-dependent transcriptional factor, is crucial for eliciting Th17 and Treg cells, and developing their immune function, particularly exerts a critical function in autoimmune diseases, such as RA. Recent researches conducted by experts on AhR have witnessed the function of AhR in regulating Th17 and Treg cell differentiation. According to the type of ligand, activation of AhR can evoke Th17 or Treg cell differentiation leading to aggravation of pro-inflammation or immunosuppression in autoimmune diseases, respectively[29-31]. It has been demonstrated that AhR activation by its high-affinity ligand 6 formylindolo[3,2-b]carbazole (FICZ) may induce Th17 cells and promote IL-17 production[11]. However, the effect of AHR on Th17 and Treg cell differentiation in AS has not been well studied.

Semaphorins consist of more than 20 proteins implicated in cell-to-cell communications divided in eight main classes[12]. Notably, recent research on semaphorins demonstrated these proteins are critical for the immune response and bone metabolism[13, 14]. Semaphorin 4D (Sema4D) was originally identified as an axon guidance molecule in the central nervous system, but Sema4D was originally identified as a T cell activation marker, constitutively expressed on T cells and regulated T cell priming in the immune system $[15,16]$. It has been showed that Sema4D is implicated in the development of rheumatoid arthritis[17]. Interestingly, Sema4D was recently identified in the bone microenvironment and demonstrated that it is a product of osteoclasts that acts on osteoblasts to inhibit bone formation, thereby breaking the balance of bone homeostasis in favor of resorption. Knockdown of Sema4D prevents bone loss, suggesting that Sema4D may be a new and potentially effective target for boneincreasing drugs $[18,19]$. Immune and bone metabolism abnormality have critical roles in the progression of AS, hinting that Sema4D might exacerbate AS. However, the involvement of Sema4D in the pathogenesis of AS has not yet been determinated. Based on the role of Sema4D reported previously, we hypothesize that Sema4D may be implicated in regulating Th17 and Treg cell differentiation through AhR activation causing inflammation response and the bone remodelling process in AS patients.

Although extensive studies on the physiological and pathological effects of Sema4D on many autoimmune diseases, the potential role of Sema4D in immunoregulation and bone remodelling in the pathogenesis of AS has not yet been reported. Thus, the present study was conducted to clarify the potential role of Sema4D in AS patients, and explore the underlying mechanism that Sema4D could enhance differentiation of pro-inflammatory Th17 cells and suppress differentiation of anti-inflammatory Treg cells through activation of the AhR, which requires Sema4D-CD72 interaction.

\section{Subjects And Methods}

\section{Study subjects}

Serum samples from 56 patients with AS(42 men and 14 women) and 43 age- and sex-matched healthy controls were collected with informed consent in accordance to the Declaration of Helsinki principles for 
research involving human subjects and with approval by the local ethics committee of Nanjing Medical University. AS patients fulfilled the 1984 modified New York criteria for diagnosis of AS without previous systemic treatment[20,21]. There were neither systemic diseases, autoimmune diseases, active infectious process, known history of bone fractures in the previous 24 months and history of neurological cognitive disease, nor history of osteoporosis among all subject. We tracked the expression of sema4D in 20 patients who were treated with a TNF-a blocker after enrolment at the present study to compare sema4D expression levels before and after anti-TNF-a treatment. Patient serum specimens were stored at $-80^{\circ} \mathrm{C}$ until analysis described below. PBMCs from healthy donors and patients with AS were isolated by discontinuous density-gradient centrifugation, washed twice in sterile phosphate buffered saline (PBS) and resuspended at a concentration of $1 \times 10^{6} \mathrm{cells} / \mathrm{ml}$ PBS.

\section{Clinical and laboratory assessment}

We recorded the duration of disease, BMI, sex, age, and extraarticular manifestations of AS patients. Disease activity of AS was calculated as CRP and Bath AS disease activity index(BASDAI). BAP (San Diego, California, USA), osteocalcin (Nordic Biosciences, Herlev, Denmark), TRACP-5b and C-terminal cross-linking telopeptide of type I collagen (CTX)(Nordic Biosciences) were evaluated as markers of bone turnover. Serum BAP and TRACP-5b levels were measured by enzyme linked immunosorbent assay. Osteocalcin and CTX were measured by electrochemiluminescence immunoassays (ECLIAs)[22]. The intraassay and inter-assay coefficients of variation were below $9 \%$ for all parameters. The assay was performed according to the manufacturer's instructions. Complete blood count and routine biochemical analysis and HLA-B27 were studied.

\section{Serum Sema4D levels and cytokine analysis}

The serum concentrations of Sema4D were determined using commercially available ELISA kits (MyBioSource, San Diego, USA). Assessment was performed according to the manufacturer's instructions. The levels of soluble IL-17, IL-22 and IL-10 were measured using ELISA kits for each cytokine (R\&D Systems, $\mathrm{MN}, \mathrm{USA}$ ). All measurements were performed in triplicate.

\section{CD4+ T Cell Purification and Stimulation}

PBMCs were isolated from the blood samples freshly obtained from AS patients and healthy controls by lymphocyte separation medium(San Diego, California, USA), according to the manufacturer's instruction. Isolation of $\mathrm{CD}^{+} \mathrm{T}$ cells from PBMCs was performed by magnetic cell separation. MACS CD4 microbeads (Miltenyi Biotec, Auburn, CA, USA) were incubated with the PBMCs and applied to a MidiMACS separation column (Miltenyi Biotec, CA, USA)(Miltenyi Biotec), according to the manufacturer's instructions.

The purity of isolated $C D 4^{+} T$ cells was determined by flow cytometry to be $>96 \%$ for each population. The purified CD4+ T cells were seeded in 96 -well plates at $1 \times 10^{6}$ cells per well and then stimulated with or without soluble human Sema4D-Fc fusion protein(PeproTech, RockyHill, NJ), Plexin B2 antibody, Plexin 
B1 antibody or CD72 ligation antibody (BU40; Santa Cruz Biotechnology, USA). To assay in vitro Th17 differentiation[23], cells were activated for Th17 differentiation with anti-CD3 $(2 \mu \mathrm{g} / \mathrm{ml}$, plate-bound), antiCD28 $(2 \mu \mathrm{g} / \mathrm{ml}$, soluble). For blocking assays, cells were cocultured with $10 \mathrm{ng} / \mathrm{ml}$ of Sema4D-Fc and 10 $\mathrm{ng} / \mathrm{ml}$ of anti-Sema4D antibody or isotype-matched control IgG for 48 hours. Concentrations of human IL-10, IL-22 and IL-17 in culture supernatants were tested by ELISA. At the end of the stimulation period, cells were collected and analyzed by flow cytometry, Quantitative RT-PCR analysis was performed as above description..

\section{Flow Cytometric Analysis}

CD4+ T Cells were harvested before and after stimulation. Cell surface markers were stained with the indicated labeled antibodies against indicated cell surface antigens. Cells were prepared in heparinized tubes by Ficoll-Paque density-gradient centrifugation and then analyzed on a FACSCanto (Invitrogen, CA, USA) using FlowJo software(Tree Star) according to the manufacturer's instructions. The following flow cytometry antibodies were used for the analyzing cell type and cytokine production: PE-CD4, Foxp3-APC, CD25-PE and FITC-IL-17A (BioLegend, California, USA). FITC-, PE- and APC labeled mouse IgG were utilized as isotype controls (Bio-Legend, California, USA).

\section{Proliferation assay}

For the proliferation assay, isolated $\mathrm{CD} 4^{+} \mathrm{T}$ cells were labeled with the Cell TraceTM CFSE Cell Proliferation Kit (Invitrogen, CA, USA) at a final concentration of $4 \mu \mathrm{M}$. CFSE-labeled CD $4^{+}$T cells were incubated under the described conditions. $1 \times 10^{6}$ million of CFSE-labeled T cells, were seeded into a flat 96-well plate. Soluble anti-sema4D (see above), soluble anti-CD72 (Biolegend, San Diego, CA, USA), or matched isotypes were added as indicated. T cell proliferation was recorded after 3 days and 5 days, based on CFSE dilution using flow cytometry.

\section{Western blot assay}

Cells were collected after induction and cell lysate was prepared from $1 \times 10^{7}$ cells. The proteins were resolved by SDS-PAGE and transferred to polyvinylidene fluoride membranes (Sigma, USA). The membrane was blocked in $5 \%$ bovine serum albumin or nonfat dry milk in Tris-buffered saline for $2 \mathrm{~h}$ at room temperature, then incubated with mouse primary antibodies overnight at $4^{\circ} \mathrm{C}$. The membrane was washed and incubated with primary antibodies against CYP1A1 or $\beta$-actin (all from Cell Signaling Technology, Danvers, MA, USA), and horseradish peroxidase-conjugated secondary antibodies were added. Then, the bands were detected using ECL luminescent reagents (Pierce, USA). GAPDH was used as a loading control.

\section{RNA extraction and real-time quantitative PCR (qPCR)}

To detect levels of IL-17A, ROR- $y$ t, Foxp3, and GAPDH mRNA expression, total RNA from human PBMCs and CD4+ T cells was extracted using the QIAGEN RNeasy Mini Kit (QIAGEN, Hilden, Germany), and 
complementary DNA (cDNA) was synthesized using a Super-Script II cDNA synthesis kit (Invitrogen, USA) according to the manufacturer's protocols. Quantitative RTPCR analysis was performed using the QuantiFastTM SYBR Green PCR Kit (QIAGEN, Hilden, Germany) with an ABI 7500 instrument (Applied Biosystems, CA, USA). The primer sequences were as follows: IL-17, forward, 5'-

CGGACTGTGATGGTCAACCTGA-3',reverse,5'-GCACTTTGCCTCCCAGATCACA-3'; FoxP3,forward,5'GGCACAATGTCTCCTCCAGAGA-3',reverse,5'-CAGATGAAGCCTTGGTCAGTGC-3';ROR-үt,forward,5'CAGAATGACCA-GATTGTGCTT-3',reverse,5'-TCCATGCCACCGTATTTGC-3';AhR,forward,5'CAAATCAGAGACTGGCAGGA-3',reverse,5'-AGAAGACCAAGGCATCTGCT-3';CYP1A1,forward, 5'GTTCTTGGAGCTTCCCCGAT-3', reverse,5'-CTGACACGAAGGCTGGAAGT-3', andGAPDH,forward,5'GTCTCCTCTGACTTCAACAGCG-3',reverse,5'-ACCACCCTGTTGCTGTAGCCAA-3'. All reactions were carried out in triplicate in the same plate.

\section{Cell culture and Luciferase assay}

The EL-4 cells were cultured at $37^{\circ} \mathrm{C}$ and $5 \% \mathrm{CO} 2$ in RPMI1640(Gibco, USA) supplemented with $10 \%$ heatinactivated fetal bovine serum. The EL- 4 cells were plated in 96 -well plates $\left(1 \times 10^{6}\right.$ cells per well), and the cells in each well were co-transfected with a vector, pGL3 [luc2P/XRE/Hygro] , containing a xenobiotic responsive elements (XRE) that drives transcription of the luciferase reporter geneluc 2P (Photinuspyralis) was used[24]. Fresh culture media were added to the cells along with $\operatorname{FICZ}(300 \mathrm{nM})$, Sema4D(10ng/ml), anti-PlexinB1 $(5 \mu \mathrm{g} / \mathrm{ml})$, anti-PlexinB2 $(5 \mu \mathrm{g} / \mathrm{ml})$, anti-CD72 $(5 \mu \mathrm{g} / \mathrm{ml})$ or $\mathrm{CH} 233191(30 \mu \mathrm{M})$, either alone or in combination, and incubated for $12 \mathrm{~h}$. The cells were washed and lysed, and the supernatants were collected from the lysed cell preparations. The luciferase activity was measured by a luciferase assay system (Promega, Madison, WI, USA) and a multimode reader according to the manufacturer's instructions.

\section{Ethoxyresorufin-0-deethylase (EROD) activity}

The EL-4 cells were plated into 6-well plates at a density of $1 \times 10^{6} \mathrm{cells} / \mathrm{mL}$, and stimulated with Sema4D, anti-PlexinB1, anti-PlexinB2, anti-CD72, CH223191, and FICZ either alone or in combination, and incubated for $24 \mathrm{~h}$, and supernatant was collected. Then, CYP1A1 activity was measured by using the EROD enzyme assay, as previously described[25]. Fluorescence intensity was detected by using a FL600 plate reader (Biotek, Winooski, VT, USA), with excitation at $530 \mathrm{~nm}$ and emission at $590 \mathrm{~nm}$.

\section{Statistical Analysis}

Statistical significance was calculated using SPSS 20.0. Nonparametric Mann-Whitney U tests were used to compare 2 groups, and comparisons between 3 groups were performed using the Kruskal-Wallis test followed by the Mann-Whitney $\mathrm{U}$ test. The correlation analysis was performed using the Pearson correlation test. For all statistical analyses, $\mathrm{p}$ values less than 0.05 were considered significant.

\section{Results}




\section{Sema4D levels were significantly elevated in patients with AS}

Recently, immune sema4D play critical roles in diverse pathological processes in many chronic inflammation diseases, such as rheumatoid arthritis. However, its specific role in the modulation of immune inflammation in AS are not elucidated yet. To survey the pathologic implications of Sema4D in patients with AS, we measured serum levels of Sema4D in AS patients and healthy controls. As shown in Fig.1A, serum levels of soluble Sema4D were significantly higher in AS patients than in healthy controls (mean $\pm S D$ 66.7 $\pm 6.9 \mathrm{ng} / \mathrm{ml}$ versus $26.8 \pm 3.9 \mathrm{ng} / \mathrm{ml} ; P<0.01$ ). Importantly, serum Sema4D levels were significantly decreased after 2 months treatment with a TNF-a blocker. Previous reports showed that the levels of IL-17 in AS patients were significantly higher than those in the control group, but those of sclerostin were significantly lower. The present results are consistent with the previous reports. Clinical data and baseline demographic findings of participants are presented in Table1. Serum concentrations of soluble Sema4D were significantly correlated with Bath AS disease activity index (BASDAI), CRP and serum IL-17 levels ( $r=0.422$ and $p<0.001$ for BASDAl; $r=0.330$ and $p<0.001$ for CRP; $r=0.561$ and $p<0.001$ for IL-17) (Fig. 1B,D,C). However, there were no significant correlations between soluble Sema4D levels and those of sclerostin (not shown).

\section{Correlation between serum Sema4D and serum bone remodelling marker levels}

Growing data have identified Sema4D as a product of osteoclasts, which tipped the balance of bone homeostasis in favor of resorption and involved in the bone remodelling process[19, 26]. To determine whether serum Sema4D was correlated with serum bone remodelling marker levels in AS patients, we detected serum levels of bone remodelling markers. The results showed that Serum levels of BAP, TRAP $5 \mathrm{~b}, \mathrm{CTX}-\mathrm{I}$ and OC in AS patients were significantly elevated compared with healthy controls $(1123 \pm 98.7 \mathrm{vs}$ $877.9 \pm 49.5 \mathrm{pg} / \mathrm{ml}, \mathrm{P}<0.001 ; 1869 \pm 169.3$ vs $1672 \pm 112.8 \mathrm{pg} / \mathrm{L}, P<0.001 ; 1.92 \pm 0.45$ vs $1.2 \pm 0.23 \mathrm{ng} / \mathrm{ml}$, $\mathrm{P}<0.01 ; 14.2 \pm 4.7$ vs $13.1 \pm 5.3, \mathrm{P}=0.057$, respectively). More importantly, significant positive correlations were found between serum Sema4D level and serum levels of bone turnover markers CTX-I, TRAP $5 \mathrm{~b}$ and $\operatorname{BAP}(r=0.347, P<0.001 ; r=0.433, P<0.001 ; r=0.293, P=0.009$, respectively)(Fig. $1 E, F, G)$, whereas there were no correlations between serum Sema4D and serum levels of bone formation markers OCN. Also, no significant correlations between serum Sema4D levels and age, BMI were found. These data suggested that Sema4D played a critical role in bone resorption and might involved in the pathogenesis of bone loss in AS patients.

\section{Sema4D expression in the CD4 ${ }^{+} \mathrm{T}$ cells of AS patients}

It has been reported that Sema4D shows higher expression levels on T cells compared to other lymphocytes such as B cells in RA patients. Besides, the expression is further enhanced after cellular activation[27, 28]. However, the role of Sema4D in the pathogenesis of AS have not been undefined. Then, PBMCs were isolated from AS patients and healthy controls, Sema4D expression were detected in PBMCs from AS patients and healthy controls by flow cytometry. Cell-surface membrane-bound Sema4D was abundantly expressed on CD4+ T cells and at lower levels on CD19+ B lymphocytes in healthy 
individuals. By contrast, cell-surface expression of Sema4D was significantly downregulated on CD4+ T cells from AS patients compared with healthy donors (Fig. 1H). Interestingly, qRT-PCR revealed that the mRNA expression of Sema4D on CD4+ T cells was elevated in AS patients (Fig. 1J), suggesting the increased serum soluble Sema4D levels and the reduced cell-surface membrane-bound Sema4D levels on CD4+ $T$ cells in patients with AS were due to the shedding of Sema4D from the activated T cells surface. As Sema4D expression was significantly enhanced in CD4+ T cells of PBMCs from AS patients, we then analyzed the expression of other cytokines or transcription factors expression on CD4+ T cells of PBMCs derived from AS patients. Our data revealed that the mRNA expression of IL-17A and RORyt were increased, whereas the mRNA expression of Foxp3 was reduced on CD4+ T cells of PBMCs derived from AS patients (Fig. 1K).

\section{Sema4D promotes CD4+ T cell proliferation and Th17 cell differentiation, Whereas inhibits Treg cell differentiation}

Previous reports suggested that soluble Sema4D exerts multiple effects on CD4+ T cells in several diseases[29, 30], so we speculated that Sema4D may also have effects on CD4+ T cells in AS patients. CD4+ $T$ cells were harvested from PBMCs derived from AS patients and healthy donors, stained with CFSE, then co-cultured with or without soluble human Sema4D-Fc in the presence of anti-Sema4D or isotype control. After 3 days, the proliferation rate and proportion of T cells subsets were detected by flow cytometry. Of note, after being stimulated with Sema4D, CD4+ T cells showed a significant proliferation in AS patients (Fig. 2A,B), which was remarkably restrained by adding soluble anti-Sema4D.

To further explore the effect of Sema4D on CD4+ T cells subsets, Th17 and Treg cell differentiation, we tested the mRNA expression of transcription factors using QRT-PCR. Our results revealed that the expression of RORyt, a transcriptional factor specific to Th17 cells differentiation, was significantly increased on CD4+ T cells from AS patients and healthy controls after Sema4D stimulation (Fig. 2E). Notably, we found that the expression of Foxp3, which is critical for the function and differentiation of Treg cells, was decreased on CD4+ T cells from AS patients and healthy controls after the treatment with Sema4D(Fig. 3E). Taken together, these data implied that soluble Sema4D alone can directly activate CD4+ T cells proliferation and Th17 cell differentiation even in the absence of other stimulatory cytokines. Due to the increased expression of RORyt and decresed expression of Foxp3, we next investigated whether soluble Sema4D elevated Th17 cell numbers and lowered Treg cell numbers. We used flow cytometry to measure the proportion of Treg cells and Th17 cells. Our data showed that the proportion of Th17 cells was enhanced and those of Treg cells was reduced in the CD4+ T cells from healthy individuals and AS patients after Sema4D stimulation (Fig. 2C,2D,3A,3B).

Subsequently, we examined the protein levels of molecules implicated in Th17 cell differentiation (IL-22 and IL-17) and Treg cell differentiation (IL-10) in CD4+ T cell from AS patients and healthy controls following treatment with Sema4D. It was revealed that Sema4D significantly elevated the protein levels of the IL-17 and IL-22 (Fig. 2F,G), and reduced the protein levels of the IL-10 (Fig. 3C,D,F).

\section{AhR pathway is involved in Sema4D-mediated Th17 cell and Treg cell differentiation}


Recently, an increasing number of reports have elicited that AhR played a critical role in the regulation of Th17 and Treg cell differentiation[31, 32]. Thus, we investigated whether AhR contributes to the Sema4Dmediated the balance of Th17/Treg cells, CD4+ T cells were incubated with or without Sema4D under Th17 or Treg cell polarization conditions. AhR and the AhR target gene CYP1A1 expression were measured. Of note, Sema4D could enhance CYP1A1 activity and AhR expression under Th17 or Tregpolarizing conditions(Fig. 4A, B and C). Next, CD4+ T cells were incubated with or without $\mathrm{CH}-223191$ (AhR antagonists) in the presence of Sema4D. We found that AhR antagonists markedly diminished the enhanced effect of Sema4D on the expression of the IL-17 and RORyt mRNA (Fig. 4D and E), and increased the IL-10 and Foxp3 mRNA expression(Fig. 4F and G). Furthermore, our results showed that the proportion of Th17 cells was reduced and those of Treg cells was elevated in the CD4+ T cells from healthy individuals and AS patients after stimulation with Sema4D and AhR antagonists comparing to stimulation with Sema4D(Fig. $4 \mathrm{H}$ and J). All these data suggested that Sema4D-promoted expression of CYP1A1 might be dependent on AhR pathway activation.

To further evaluate effect of Sema4D on the AhR pathway, we explored the activation of AhR pathway by Sema4D in EL-4 cells with anti-CD3/CD28 antibodies treatment. Results showed that Sema4D enhanced the protein and mRNA expression of CYP1A1, and the enzymatic activity of CYP1A1 under Th17 or Treg cell polarization conditions (Fig.5A, B and C), suggesting that it might implicate in activation of AhR pathway in lymphocyts. Subsequently, we performed blocking assay using AhR antagonist $\mathrm{CH} 233191$. AhR antagonist was shown to decreased Sema4D-induced CYP1A1 enzymatic activity and the mRNA and protein expression of CYP1A1 (Fig.5E, F and D). These results suggested that Sema4D-mediated effects on CYP1A1 were dependent on AhR. To further confirm that the Sema4D-mediated CYP1A1 activity was attributed to the increasing of XRE (AhR-dependent reporter gene) reporter activity, we transfected EL-4 cells with an XRE-driven luciferase reporter gene. Sema4D was shown to promote the reporter gene, which occurred through AhR activation (Fig. 5G). These findings revealed that Sema4D could significantly promote AhR binding to a specific XRE sequence and that AhR was a key factor in the Sema4D-mediated Th17 cell and Treg cell differentiation.

\section{Sema4D-CD72 interaction is required for cytokine production and AhR activation}

As Th17-related cytokines, IL-17 and IL-22, played a critical role in the pathogenesis of AS patients, we then analyzed the effect of Sema4D on the cytokine production profile of T cells. Culture supernatants were collected after the CD4+ T cells were incubated with or without Sema4D. Our results showed that IL17 and IL-22 cytokines levels were markedly elevated after Sema4D stimulation (Fig. 2F,G).

It was believed that the effects of Sema4D are regulated via three receptors: Plexin B1, Plexin B2, and CD72[33]. To investigate which receptor was involved in the stimulatory effect of Sema4D observed in CD4+ T cells, we firstly evaluated the transcriptional expression of PLXNB1, Plexin B2, and CD72 on CD4+ $T$ cells derived from patients with AS and healthy subjects by quantitative RT-PCR and noticed the mRNA levels of CD72 were evidently upregulated comparing to that of PLXNB2 and PLXNB1 after Sema4D stimulation (Fig. 6A). Then, we measured cell-surface expression of CD72 protein on CD4+ T cells derived 
from AS patients by flow-cytometry and found CD72 expression to be increased on CD4+ T cells derived from AS patients and healthy controls after Sema4D stimulation(Fig. 6B).

To further address the role of CD72 in Sema4D-mediated cytokine production and AhR activation, blocking assays were conducted with anti-Plexin B1 or anti-Plexin B2 or anti-CD72 antibody. The CD4+ T cells were stimulated with Sema4D or anti-plexin B1 or anti-plexin B2 or anti-CD72 antibody, and cytokine production was tested. Our results revealed that Sema4D-induced cytokine secretion was significantly suppressed in the CD4+ $T$ cells by adding the anti-CD72 antibody compared with control cells in in the presence of the anti-plexin B1 or anti-plexin B2 antibody(Fig. 6C,D). Furthermore冈it was shown that incubation with anti-CD72 antibody remarkably attenuated the Sema4D-induced XRE-dependent luciferase reporter gene expression and CYP1A1 enzymatic activity and mRNA expression(Fig. 6F,G,E). These findings suggested that Sema4D may induce cytokine secretion and AhR activation by CD4+ $T$ cells via interactions with $C D 72$ receptor. These observations further reinforce that CD72 may be the major receptor for the effect of Sema4D induced signal to CD4+ T cell derived from AS patients proliferation and differentiation.

\section{Discussion}

Here, we found that Serum Sema4D was significantly increased in peripheral blood of AS patients. These data presented suggested that Sema4D might be involved in the pathogenesis of AS in some way. Although recent reports showed that serum Sema4D levels are elevated in other disease states and animal models, the role of Sema4D in AS patients are not elucidated yet. Our results highlighted the pathological significance of Sema4D in the pathogenesis of AS, providing basic and clinical implications.

Previous studies suggested that soluble Sema4D levels were elevated in RA patients and high soluble Sema4D levels related to clinical and biologic markers of RA. Therefore, we investigated the role of Sema4D in the pathogenesis of AS. In the current study, we confirmed that Serum levels of Sema4D were significantly increased in patients with AS and positively correlated with the disease activity marker of AS, such as CRP and BASDAI. We also observed that the change of soluble Sema4D levels before and after treatment of AS with a TNF-a blocker and found that decrease in the soluble Sema4D levels of AS patients with successful treatment were positively correlated with lower in clinical disease activity. Our data reveal the possibility of Sema4D as an additional clinical disease marker for the evaluation of of AS activation status. Recent reports showed that the expression of Sema4D was elevated in osteoclasts, and prompted bone resorption by activating osteoclasts. In current study, we tested the levels of several serum bone markers to explore if bone formation or bone resorption were affected by Sema4D in AS patients. The data showed that the resorption index, CTX and TRAP 5b, which indicates the osteoclast activity, were significantly elevated and correlated with serum Sema4D levels in AS patients. However, there was weak correlation between serum Sema4D levels and the bone formation markers osteocalcin and BAP. Together, these results suggest that Sema4D may augment the bone resorption in AS patients. Further work will be needed to ascertain the exact role of Sema4D in bone loss in AS. 
Immune inflammation in AS is classically characterized by inflammatory pathways involving innate and adaptive immune responses. The feature of this immune inflammation is driven by $T$ cells, especially involving CD4 + T cell phenotypes. Significant

increases of Th17 and significant decreases of Treg in peripheral blood of AS patients were found to be responsible for the pathogenesis of AS. As recent reports indicated that Sema4D was mainly expressed in $T$ cells, we detected cell surface expression of Sema4D by flow cytometer and mRNA expression of Sema4D by qRT-PCR. Intriguingly, cell-surface expression of Sema4D was significantly reduced, whereas mRNA expression of Sema4D was elevated on CD $4+T$ cells from AS patients. It has been reported that this relative reduction in cell surface levels of Sema4D was attributed to shedding of Sema4D from the CD4 + T cell surface. Collectively, our results support that the reduction of cell surface membrane-bound Sema4D is crucially implicated in the development of AS and prompt us to investigate the effect of Sema4D on CD4 $+T$ cell proliferation and differentiation.

Consistent with previous reports, our data confirmed the proportion of Th17 cells is significantly increased in the PBMCs of AS patients. Next, we investigated the function of Sema4D during CD $4+T$ cell proliferation. After being stimulated with Sema4D, CD4 + T cells showed a significant proliferation in a purified CD $4+T$ cell culture system from AS patients. However, this proliferation was significantly suppressed by adding soluble anti-Sema4D. Next, we observed the effects of Sema4D on Th17 cells frequency and secreted cytokines in AS patients, found that secretion level of IL-17 and mRNA expression level of IL-17 and RORyt in CD 4 + T cells after soluble sema4D treatment were markedly elevated in AS patients. In addition, Tregs are essential for suppressing excessive autoimmune responses, thereby maintaining immune homeostasis. Our findings supported that Sema4D could restrain Foxp3 and IL-10 expression, suggesting a role of Sema4D involvement in the impaired function of Treg cells in AS patients. These data revealed that Sema4D might be implicated in the pathogenesis of AS through inducing T cell proliferation, regulating Th17 and Treg cells differentiation and reinforcing the function of Th17 cell. Collectively, the current findings further illuminated the immune-regulatory mechanism of Sema4D, which causes the Th17/Treg imbalance.

Recently, AhR has attracted researchers attention for its wide-spectrum expression in immune system cells such as certain subtypes of T cells, Th17 and Treg cells. It has been shown that AhR was involved in critical immune regulation functions. In many autoimmune diseases, AhR activation is the crucial factors regulating the differentiation of Th17 and Tregs cells. Thus, we speculated that Sema4D might regulate Th17 and Treg cells differentiation dependent on activation of AhR to accelerate AS development. Here, we found that Sema4D enhanced the expression of AhR and CYP1A1 (the AhR target gene) in AS patients. Notably, Pretreatment of Sema4D-exposed cells with AhR antagonist significantly decreased the expression of Cyp1A1 and suppressed the regulatory effect of Sema4D on Th17 and Treg differentiation. Moreover, Sema4D could potentiate CYP1A1 enzymatic activity via AhR pathway. Meanwhile, we conducted a further detailed analysis and verified that Sema4D-induced CYP1A1 activity was ascribed to the enhancement of an AhR-dependent reporter gene. These results further corroborated that Sema4D could induce activation of AhR pathway to modulate Th17 and Treg differentiation in AS patients. 
It has been reported that Sema4D functions as a ligand and interacts with three different receptors: Plexin-B1, Plexin-B2, and CD72. To address which receptor was involved in Sema4D-induced activation of AhR, we firstly measured the expression of PlexinB1, PlexinB2, and CD72 in activating $T$ cells and noticed that CD72 is the main Sema4D receptor in CD4 + T cells from AS patients. Next, we found that soluble anti-CD72 significantly inhibited the mRNA expression of CYP1A1 and XRE reporter activity in CD4 + T cell in the presence of Sema4D, and the levels of cytokine secretion were suppressed. These data implied that the increase in activation of AhR and cytokine production promoted by Sema4D depends on its interaction with CD72 receptor.

\section{Conclusions}

This work is the first to report the role of Sema4D in AS patients. Our results showed that the serum levels of secreted Sema4D were significantly high in AS patients and that Sema4D is a potential biomarker for AS disease. Furtherly, our studies were performed to unravel the mechanism how enhanced Sema4D levels play a role in regulating the immune response in AS patients. Therefore, further studies should also address the problem of whether it could serve as a potential therapeutic target for AS patients.

\section{Abbreviations}

AS:Ankylosing Spondylitis; AhR:aryl hydrocarbon receptor; CRP:C-reactive protein; ELISA:Enzyme-linked immunosorbent assay; FACS:Fluorescence-activated cell-sorting; IgG:Immunoglobulin G; IL-17:Interleukin17; IL-22:Interleukin-22; mAb:Monoclonal antibody; mRNA:Messenger RNA; PBMC:Peripheral blood mononuclear cell; PE:phycoerythrin; RORyt:Retinoic acid receptor-related orphan nuclear receptoryt; RTPCR:Reverse transcription-polymerase chain reaction; Sema4D:Semaphorin 4D; sSema4D:Soluble semaphorin 4D; Th17:T-helper cell type 17; CTX: $\beta$-isomerized carboxy-terminal telopeptide of type-I collagen; TRACP-5b:isoform $5 \mathrm{~b}$ of tartrate resistant acid phosphatase; BAP:bone alkaline phosphatase; Treg cells:regulatory T cells ; EROD:Ethoxyresorufin-O-deethylase;CH223191:1-Methyl-N-[2-methyl-4-[2-(2methylphenyl)diazenyl]phenyl-1 H-pyrazole-5-carboxamide; FICZ:6-formylindolo[3,2-b]carbazole;

\section{Declarations}

\section{Acknowledgements}

The authors would like to thank the study participants; the staff involved in the collection of blood samples.

\section{Funding}

This work was supported by grants from the National Natural Science Foundation of China (30600560); The funders had no role in study design, data collection and analysis, decision to publish, or preparation of the manuscript.

\section{Availability of data and materials}


The datasets supporting the conclusions of this article are included within the article.

Authors' contributions

JMX and JRG conceived, designed the study and analyzed data. JMX planned experiment. JMX and ZTW performed in vitro experiments and participated in its design and coordination, and drafted the manuscript.. All authors read and approved the final manuscript.

\section{Competing interests}

The authors declare that they have no competing interests.

\section{Ethical approval and consent to participate}

The participants gave their written informed consent and the Regional Ethics Committee at Nanjing Medical University approved the study.

\section{Author details}

1 Department of Rheumatology, Second Affiliated Hospital of Nanjing Medical University, Nanjing, China.

2 Department of Rheumatology, the Third Affiliated Hospital of Sun Yat-sen University, Guangzhou, China

\section{References}

1. Klingberg E, Lorentzon M, Gothlin J, Mellstrom D, Geijer M, Ohlsson C, Atkinson EJ, Khosla S, Carlsten $\mathrm{H}$, Forsblad-d'Elia $\mathrm{H}$ : Bone microarchitecture in ankylosing spondylitis and the association with bone mineral density, fractures, and syndesmophytes. Arthritis Res Ther 2013, 15(6):R179.

2. Davey-Ranasinghe N, Deodhar A: Osteoporosis and vertebral fractures in ankylosing spondylitis. Curr Opin Rheumatol 2013, 25(4):509-516.

3. Davey-Ranasinghe N, Deodhar A: Osteoporosis and vertebral fractures in ankylosing spondylitis. Curr Opin Rheumatol 2018, 25(4):509-516.

4. Wang $C$, Liao Q, Hu Y, Zhong D: T lymphocyte subset imbalances in patients contribute to ankylosing spondylitis. Exp Ther Med 2015, 9(1):250-256.

5. Xueyi L, Lina C, Zhenbiao W, Qing H, Qiang L, Zhu P: Levels of circulating Th17 cells and regulatory T cells in ankylosing spondylitis patients with an inadequate response to anti-TNF-alpha therapy. $J$ Clin Immuno/ 2013, 33(1):151-161.

6. Fert I, Cagnard N, Glatigny S, Letourneur F, Jacques S, Smith JA, Colbert RA, Taurog JD, Chiocchia G, Araujo LM et al: Reverse interferon signature is characteristic of antigen-presenting cells in human and rat spondyloarthritis. Arthritis Rheumatol 2014, 66(4):841-851.

7. Beek KJ, Rusman T, van der Weijden MAC, Lems WF, van Denderen JC, Konsta M, Visman I, Nurmohamed MT, van der Horst-Bruinsma IE: Long-Term Treatment With TNF-Alpha Inhibitors 
Improves Bone Mineral Density But Not Vertebral Fracture Progression in Ankylosing Spondylitis. $J$ Bone Miner Res 2019, 34(6):1041-1048.

8. Gravallese EM, Schett G: Effects of the IL-23-IL-17 pathway on bone in spondyloarthritis. Nat Rev Rheumatol 2018, 14(11):631-640.

9. Fu J, Nogueira SV, Drongelen VV, Coit P, Ling S, Rosloniec EF, Sawalha AH, Holoshitz J: Shared epitope-aryl hydrocarbon receptor crosstalk underlies the mechanism of geneenvironment interaction in autoimmune arthritis. Proc Natl Acad Sci U S A 2018, 115(18):4755-4760.

10. Nguyen NT, Nakahama T, Kishimoto T: Aryl hydrocarbon receptor and experimental autoimmune arthritis. Semin Immunopathol 2013, 35(6):637-644.

11. Kiyomatsu-Oda M, Uchi H, Morino-Koga S, Furue M: Protective role of 6-formylindolo[3,2-b]carbazole (FICZ), an endogenous ligand for arylhydrocarbon receptor, in chronic mite-induced dermatitis. $J$ Dermatol Sci 2018, 90(3):284-294.

12. Jongbloets BC, Pasterkamp RJ: Semaphorin signalling during development. Development 2014, 141(17):3292-3297.

13. Worzfeld T, Offermanns S: Semaphorins and plexins as therapeutic targets. Nat Rev Drug Discov 2014, 13(8):603-621.

14. Zhang Y, Wei L, Miron RJ, Shi B, Bian Z: Anabolic bone formation via a site-specific bone-targeting delivery system by interfering with semaphorin 4D expression. J Bone Miner Res 2015, 30(2):286296.

15. Ke Y, Dang E, Shen S, Zhang T, Qiao H, Chang Y, Liu Q, Wang G: Semaphorin4D Drives CD8(+) T-Cell Lesional Trafficking in Oral Lichen Planus via CXCL9/CXCL10 Upregulations in Oral Keratinocytes. $J$ Invest Dermatol 2017, 137(11):2396-2406.

16. Giacobini P, Messina A, Morello F, Ferraris N, Corso S, Penachioni J, Giordano S, Tamagnone L, Fasolo A: Semaphorin 4D regulates gonadotropin hormone-releasing hormone-1 neuronal migration through PlexinB1-Met complex. J Cell Biol 2008, 183(3):555-566.

17. Yoshida Y, Ogata A, Kang S, Ebina K, Shi K, Nojima S, Kimura T, Ito D, Morimoto K, Nishide M et al: Semaphorin 4D Contributes to Rheumatoid Arthritis by Inducing Inflammatory Cytokine Production: Pathogenic and Therapeutic Implications. Arthritis Rheumato/ 2015, 67(6):1481-1490.

18. Negishi-Koga T, Shinohara M, Komatsu N, Bito H, Kodama T, Friedel RH, Takayanagi H: Suppression of bone formation by osteoclastic expression of semaphorin 4D. Nat Med 2011, 17(11):1473-1480.

19. Deb Roy A, Yin T, Choudhary S, Rodionov V, Pilbeam CC, Wu Yl: Optogenetic activation of Plexin-B1 reveals contact repulsion between osteoclasts and osteoblasts. Nat Commun 2017, 8:15831.

20. Dougados M, Logeart I, Szumski A, Coindreau J, Jones H: Evaluation of whether extremely high enthesitis or Bath Ankylosing Spondylitis Disease Activity Index (BASDAI) scores suggest fibromyalgia and confound the anti-TNF response in early non-radiographic axial spondyloarthritis. Clin Exp Rheumatol 2017, 35 Suppl 105(3):50-53.

21. Deodhar A, Strand V, Kay J, Braun J: The term 'non-radiographic axial spondyloarthritis' is much more important to classify than to diagnose patients with axial spondyloarthritis. Ann Rheum Dis 
2016, 75(5):791-794.

22. Toussirot E, Mourot L, Dehecq B, Michel F, Wendling D, Grandclement E, Dumoulin G: Paradoxical elevation of serum TRACP5b levels despite increase in lumbar spine bone mineral density during anti-TNFalpha therapy in patients with inflammatory rheumatic disease: a 2-year prospective assessment of bone mass, bone metabolism, and the trabecular bone score. Eur J Rheumatol 2017, 4(3):189-193.

23. Lee JY, Hall JA, Kroehling L, Wu L, Najar T, Nguyen HH, Lin WY, Yeung ST, Silva HM, Li D et al: Serum Amyloid A Proteins Induce Pathogenic Th17 Cells and Promote Inflammatory Disease. Cell 2020, 180(1):79-91 e16.

24. Andrieux L, Langouet S, Fautrel A, Ezan F, Krauser JA, Savouret JF, Guengerich FP, Baffet G, Guillouzo A: Aryl hydrocarbon receptor activation and cytochrome P450 1A induction by the mitogen-activated protein kinase inhibitor U0126 in hepatocytes. Mol Pharmacol 2004, 65(4):934-943.

25. Han EH, Hwang YP, Kim HG, Choi JH, Park BH, Song GY, Lee GW, Jeong TC, Jeong HG: CCAAT/ enhancer-binding protein beta activation by capsaicin contributes to the regulation of CYP1A1 expression, mediated by the aryl hydrocarbon receptor. Br J Pharmacol 2011, 164(6):1600-1613.

26. Ha YJ, Han DW, Kim JH, Chung SW, Kang EH, Song YW, Lee YJ: Circulating Semaphorin 4D as a Marker for Predicting Radiographic Progression in Patients with Rheumatoid Arthritis. Dis Markers 2018, 2018:2318386.

27. Nishide M, Nojima S, Ito D, Takamatsu H, Koyama S, Kang S, Kimura T, Morimoto K, Hosokawa T, Hayama $Y$ et al: Semaphorin 4D inhibits neutrophil activation and is involved in the pathogenesis of neutrophil-mediated autoimmune vasculitis. Ann Rheum Dis 2017, 76(8):1440-1448.

28. Zhu L, Bergmeier W, Wu J, Jiang H, Stalker TJ, Cieslak M, Fan R, Boumsell L, Kumanogoh A, Kikutani $\mathrm{H}$ et al: Regulated surface expression and shedding support a dual role for semaphorin 4D in platelet responses to vascular injury. Proc Natl Acad Sci U S A 2007, 104(5):1621-1626.

29. Wu M, Li J, Gao Q, Ye F: The role of Sema4D/CD100 as a therapeutic target for tumor microenvironments and for autoimmune, neuroimmune and bone diseases. Expert Opin Ther Targets 2016, 20(7):885-901.

30. Patnaik A, Weiss GJ, Leonard JE, Rasco DW, Sachdev JC, Fisher TL, Winter LA, Reilly C, Parker RB, Mutz D et al: Safety, Pharmacokinetics, and Pharmacodynamics of a Humanized Anti-Semaphorin 4D Antibody, in a First-In-Human Study of Patients with Advanced Solid Tumors. Clin Cancer Res 2016, 22(4):827-836.

31. Piper CJM, Rosser EC, Oleinika K, Nistala K, Krausgruber T, Rendeiro AF, Banos A, Drozdov I, Villa M, Thomson S et al: Aryl Hydrocarbon Receptor Contributes to the Transcriptional Program of IL-10Producing Regulatory B Cells. Cell Rep 2019, 29(7):1878-1892 e1877.

32. Sun L, Fu J, Lin SH, Sun JL, Xia L, Lin CH, Liu L, Zhang C, Yang L, Xue P et al: Particulate matter of 2.5 mum or less in diameter disturbs the balance of $\mathrm{TH} 17 /$ regulatory $\mathrm{T}$ cells by targeting glutamate oxaloacetate transaminase 1 and hypoxia-inducible factor 1alpha in an asthma model. $J$ Allergy Clin Immunol 2020, 145(1):402-414. 
33. Oinuma I, Katoh H, Negishi M: Molecular dissection of the semaphorin 4D receptor plexin-B1stimulated R-Ras GTPase-activating protein activity and neurite remodeling in hippocampal neurons. J Neurosci 2004, 24(50):11473-11480.

\section{Table}

Due to technical limitations, Table 1 is only available for download from the Supplementary Files section.

\section{Figures}




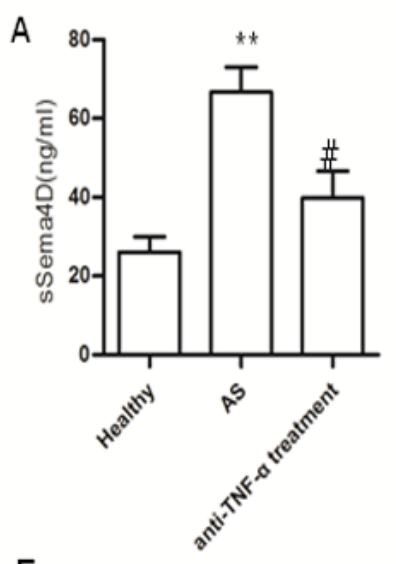

E

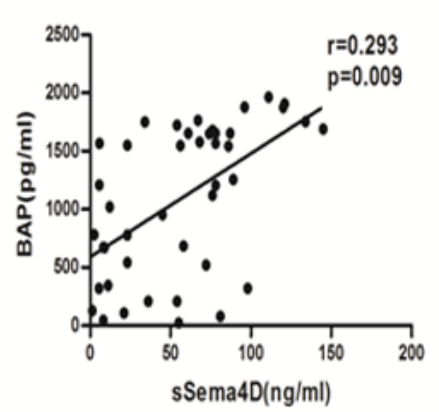

H
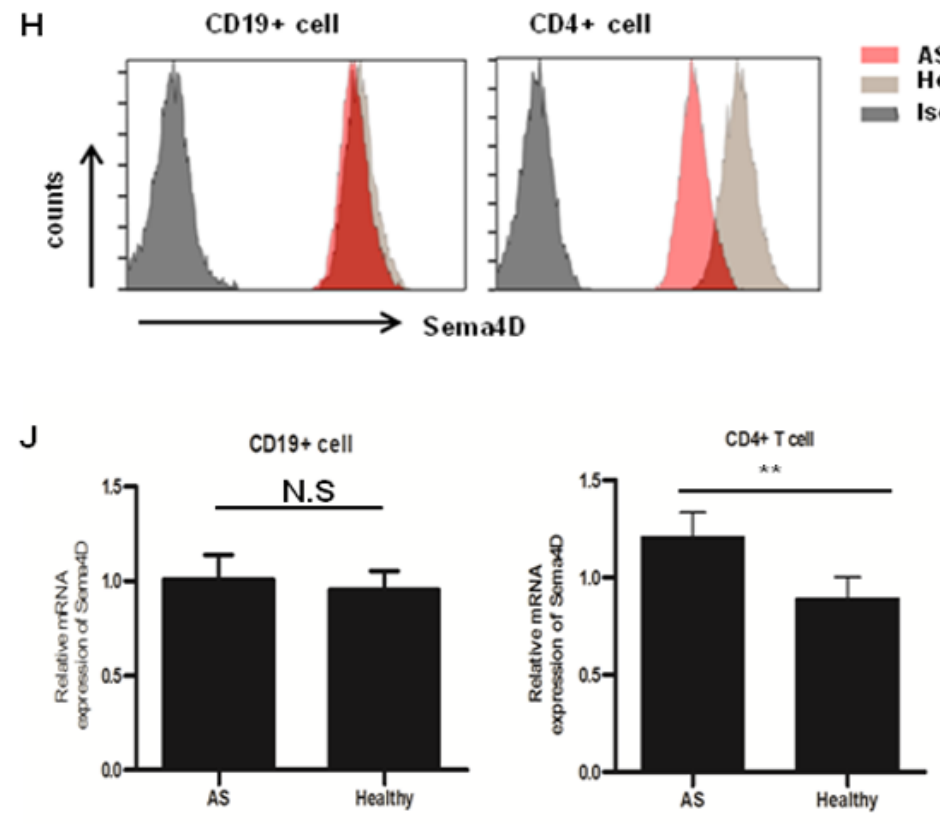

$\mathrm{F}$

G
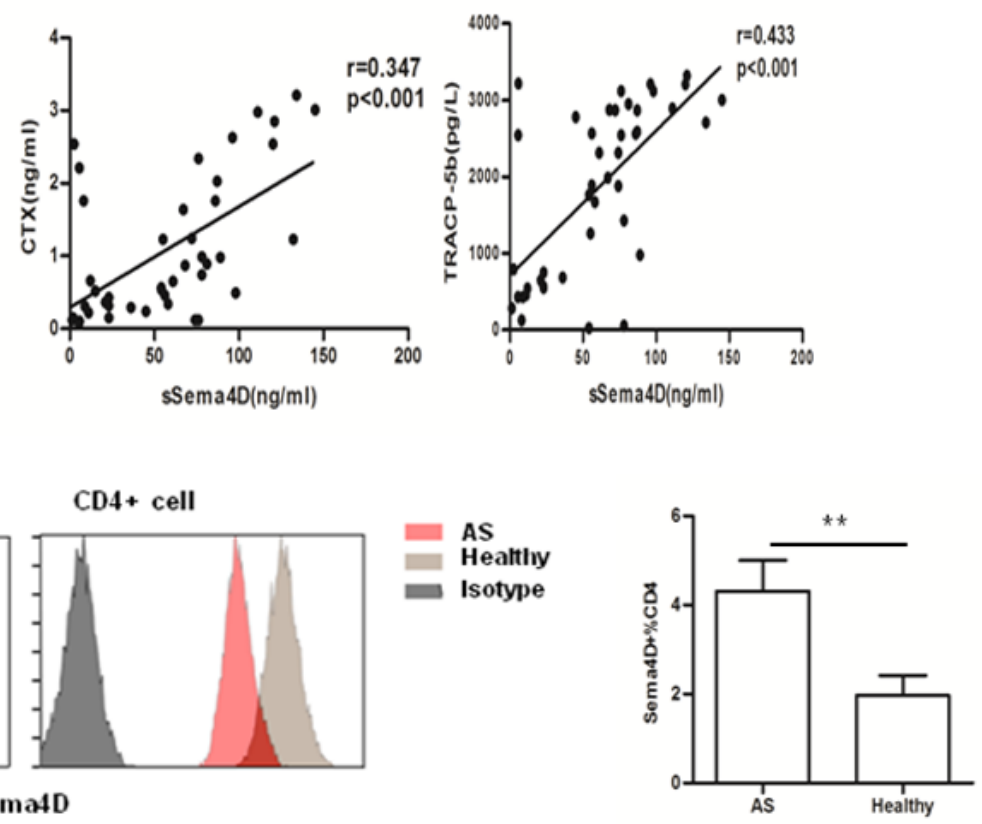

$\mathrm{K}$

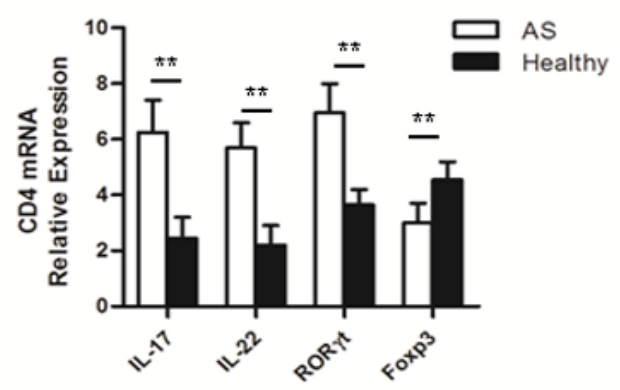

\section{Figure 1}

Sema4D and cytokine expression, and correlations of serum levels of soluble Sema4D with clinical features. (A) Serum sSema4D levels before and after anti-TNF-a treatment in 20 good responders according to the European League Against Rheumatism response criteria. ${ }^{\star *}=p<0.001$ vs Healthy; $\#=p<0.01$ vs AS. (B-D) Positive correlation of serum sSema4D levels with the Bath AS disease activity index (BASDAI), the level of IL-17, and the C-reactive protein (CRP) level. (E-G) correlation of serum 
sSema4D levels with serum bone remodelling marker levels in AS patients. $(H)$ Cell surface expression of Sema4D in peripheral blood CD4+, and CD19+ cells. Results shown are representative of findings from 6 Ankylosing Spondylitis (AS) patients and 6 healthy controls. $(\mathrm{J})$ mRNA expression of Sema4D in peripheral blood CD4+ and CD19+ cells. Results shown are from 20 AS patients and 15 healthy controls. (K) mRNA expression of IL-17, IL-22, RORyt and Foxp3 in peripheral blood CD4+ cells. Results shown are from 20 AS patients and 15 healthy controls. The data were presented as means \pm S.E.M. The results are representative of three independent experiments $* *=p<0.01$.
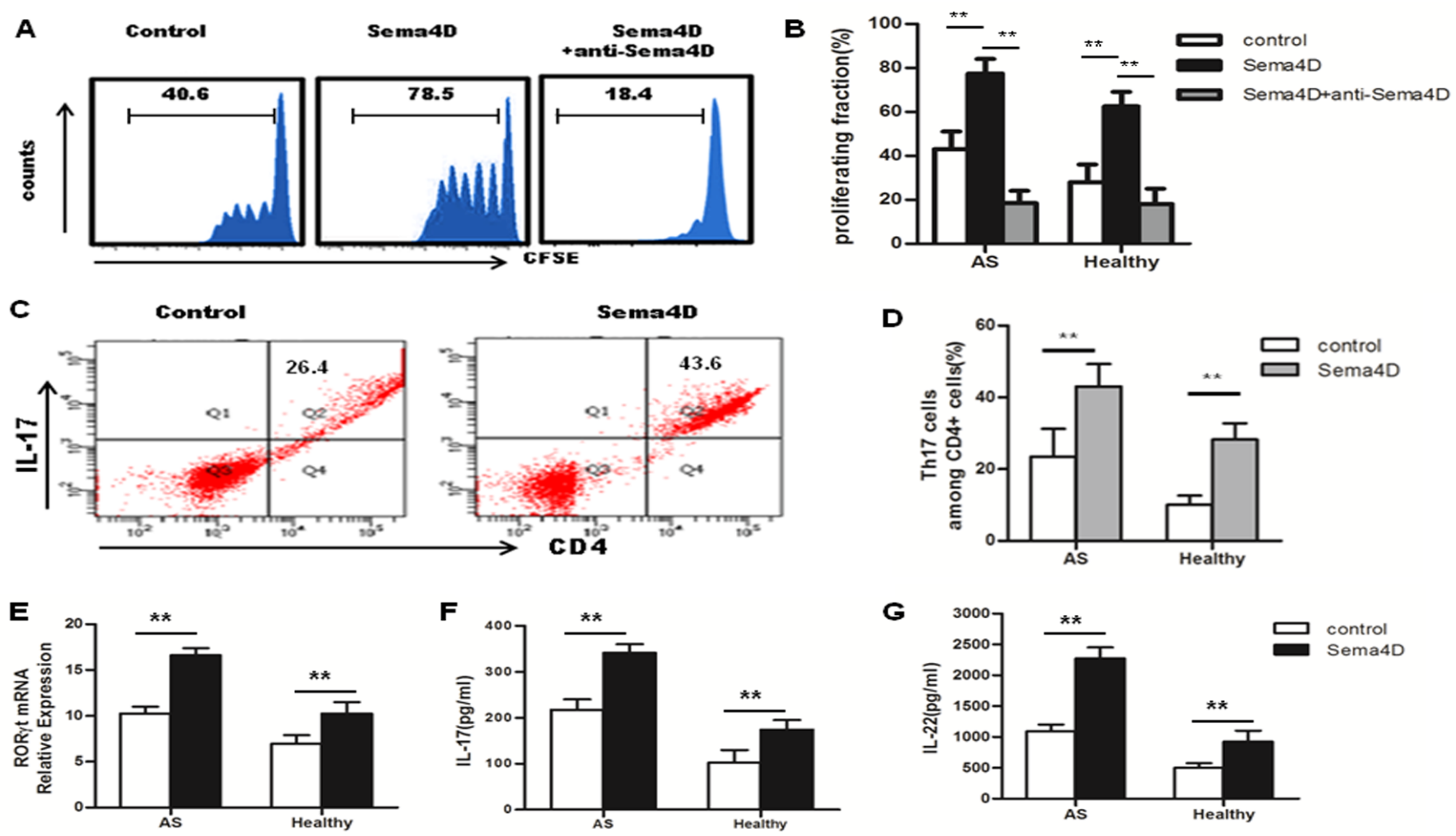

\section{Figure 2}

Sema4D promoted CD4+ T cell proliferation and Th17 cell differentiation. (A-B) CFSE labeled CD4+ T cells from AS patients $(n=20)$ and Healthy controls $(n=15)$ were treated with Sema4D $(10 \mathrm{ng} / \mathrm{ml})$ or antiSema4D antibody $(10 \mathrm{ng} / \mathrm{ml})$ for 3 days. (A) Showed a representative result of flow cytometry of AS patients. (C-D) The proportion of Th17 cells (CD4+ IL-17A+ cells) in CD4+ T cells of AS patients $(n=20)$ and Healthy controls $(n=15)$ treated with or without Seam4D $(10 \mathrm{ng} / \mathrm{ml})$ for 3 days. (C) Showed a representative result of FACS of AS patients. (E) RORyt mRNA expression in CD4+ T cells from AS patients $(n=20)$ and Healthy controls $(n=15)$ treated with or without Sema4D $(10 \mathrm{ng} / \mathrm{ml})$. (F-G) Sema4D induced Th17-related cytokines production. IL-17 and IL-22 levels in the supernatant of CD4+ T cells from AS patients $(n=20)$ and Healthy controls $(n=15)$ treated with or without Sema4D $(10 \mathrm{ng} / \mathrm{ml})$ for 3 days by ELISA. The data were presented as means \pm S.E.M. The results are representative of three independent experiments ${ }^{* *}=p<0.01$. 

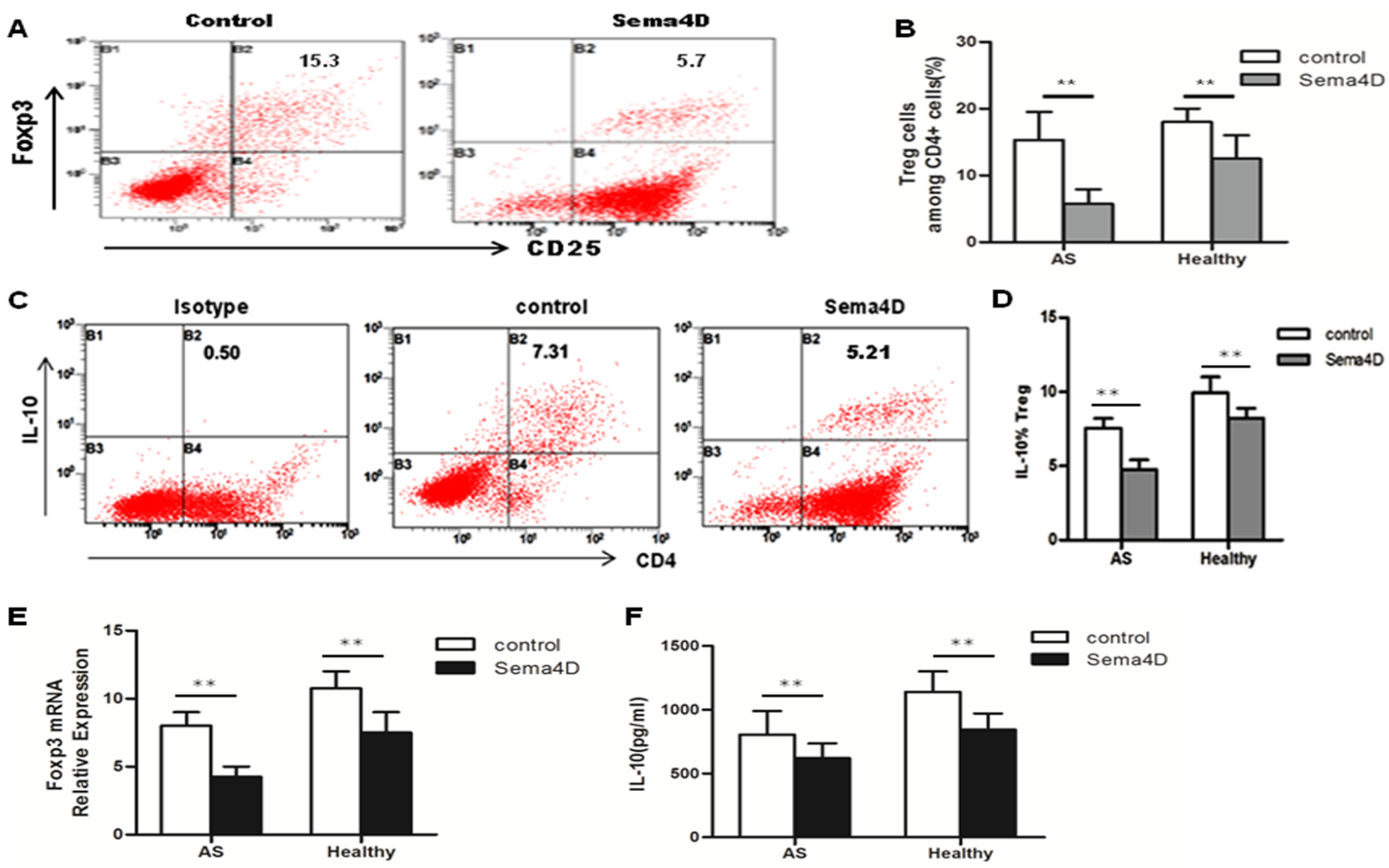

Figure 3

Sema4D $(10 \mathrm{ng} / \mathrm{ml})$ inhibited Treg cell differentiation in vitro. (A-B) The proportion of Treg cells (CD4+, CD25+, and Foxp3+ cells) in CD4+ T cells from AS patients $(n=20)$ and Healthy controls $(n=15)$ treated with or without Sema4D $(10 \mathrm{ng} / \mathrm{ml})$ for 3 days. (A) Showed a representative FACS result of AS patients. (CD) The expression of IL-10 of Treg cells in CD4+ T cells of AS patients $(n=20)$ and Healthy controls $(n=15)$ treated with or without Sema4D $(10 \mathrm{ng} / \mathrm{ml})$ for 3 days. (C) Showed a representative FACS result of AS patients. (E) Foxp3 mRNA expression in CD4+ T cells from AS patients $(n=20)$ and Healthy controls $(\mathrm{n}=15)$ treated with or without Sema4D $(10 \mathrm{ng} / \mathrm{ml})$. (F) IL-10 was quantified in the supernatant of CD4+ T cells from Healthy $(n=15)$ and AS patients $(n=20)$ treated with or without Sema4D $(10 n g / m l)$ for 3 days by $\mathrm{CBA}$. The data were presented as means \pm S.E.M. The results are representative of three independent experiments, ${ }^{* *}=p<0.01$. 

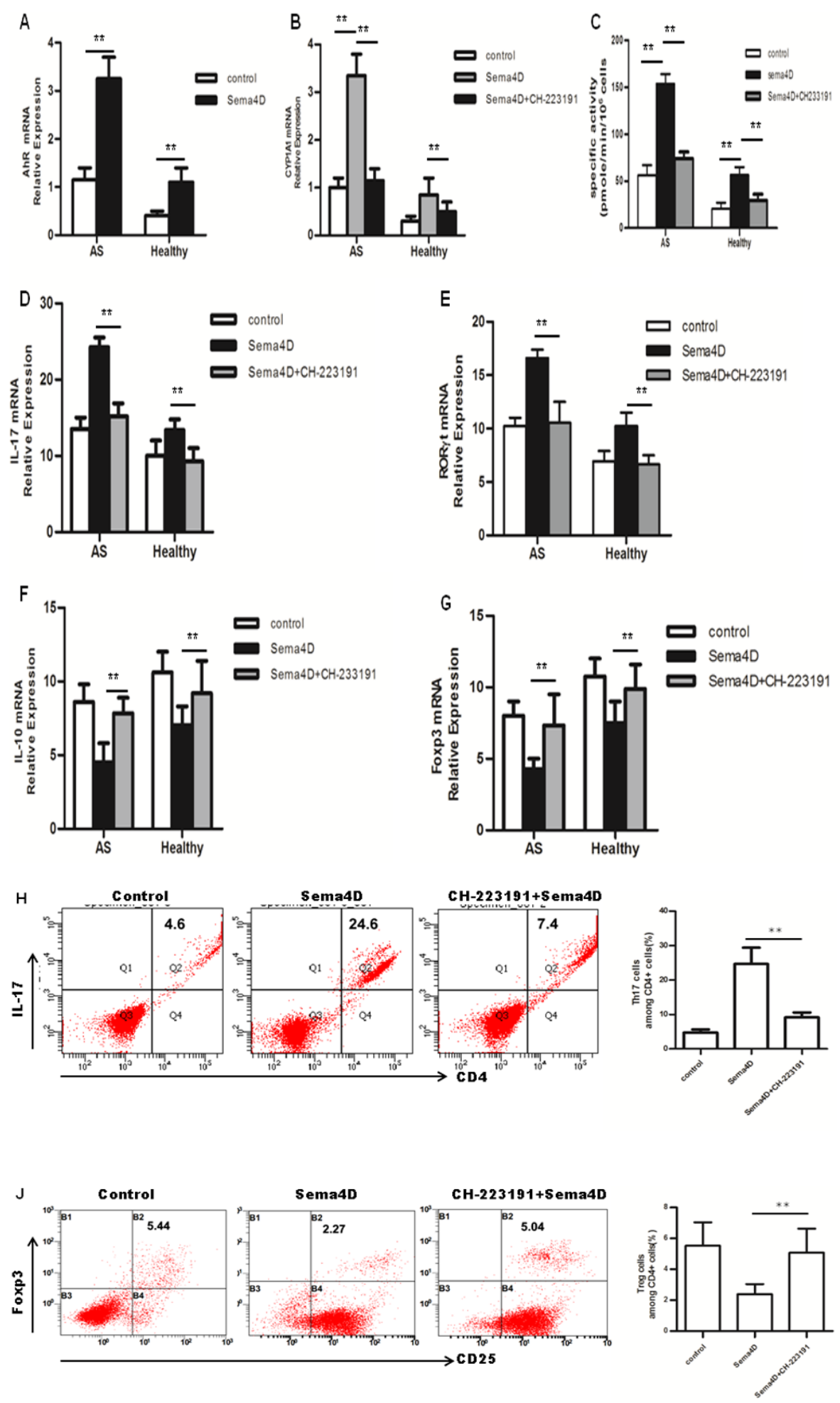

Figure 4

AhR antagonist abolished Sema4D-mediated regulation in Th17/Treg differentiation in mouse CIA. (A) The mRNA levels of AhR were analyzed in CD4+ T cells from AS patients $(n=20)$ and Healthy controls $(n=15)$ treated with or without Sema $4 D(10 \mathrm{ng} / \mathrm{ml})$ using a quantitative PCR assay. (B-C) Enzymatic activity and mRNA levels of CYP1A1 in CD4+ T cells from AS patients $(n=20)$ and Healthy controls $(n=15)$ treated with Sema4D $(10 \mathrm{ng} / \mathrm{ml})$ or $\mathrm{CH} 233191(30 \mu \mathrm{M})$ were evaluated by EROD and qPCR, respectively. (D- 
G) mRNA levels of IL-17, RORyt, IL-10 and Foxp3 in CD4+ T cells from AS patients $(n=20)$ and Healthy controls $(n=15)$ treated with Sema4D $(10 \mathrm{ng} / \mathrm{ml})$ or $\mathrm{CH} 233191(30 \mu \mathrm{M})$ were evaluated by qPCR, respectively. $(\mathrm{H}-\mathrm{J}) \mathrm{CD} 4+$ cells of AS patients were stained with antibodies against CD4/IL-17 and CD4/CD25/Foxp3. Frequency of IL-17A+ cells in CD4+ cells and frequency of CD25+Foxp3+ cells in CD4+ cells were analyzed by flow cytometry. The data were presented as means \pm S.E.M. The results are representative of three independent experiments. ${ }^{*}=p<0.01$.

A

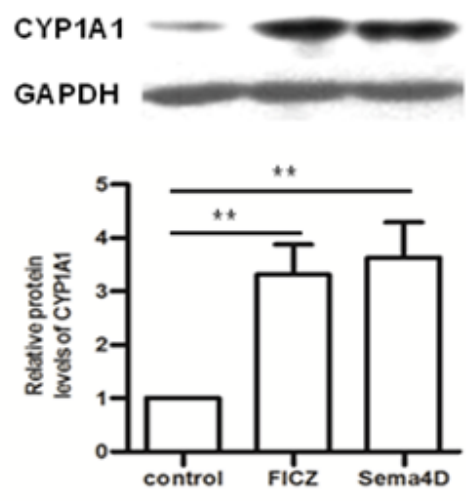

D

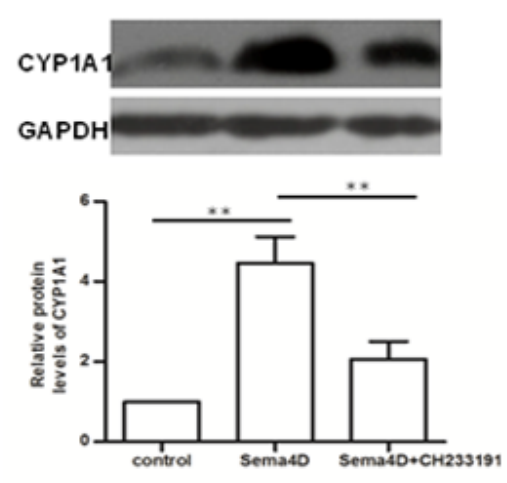

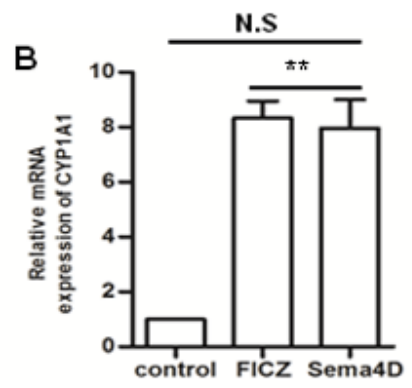

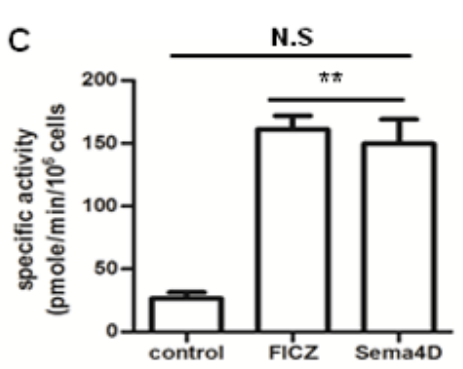

E
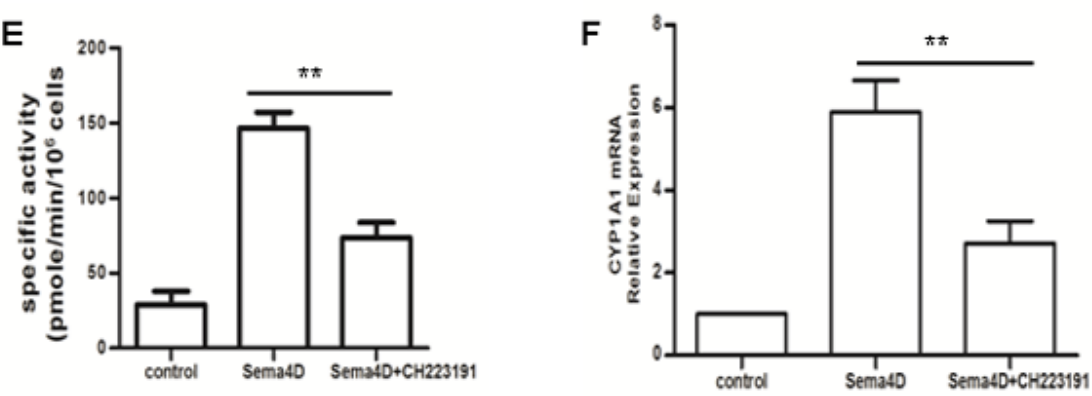

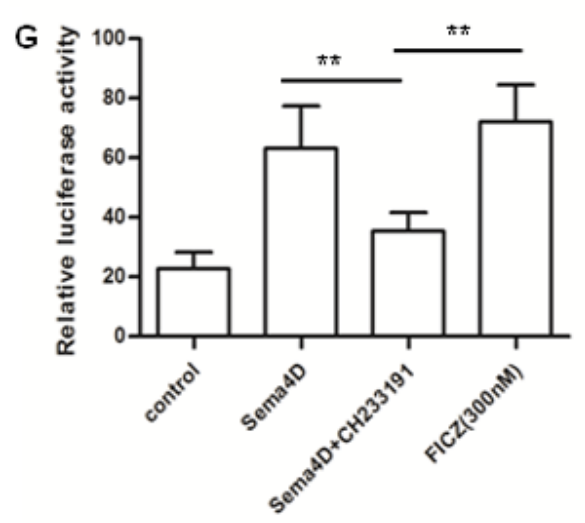

\section{Figure 5}

Effect of Sema4D on CYP1A1 activity in the EL-4 cells. (A-C) Protein, mRNA and enzymatic activity levels of CYP1A1 were analyzed using Western blot, QPCR and EROD assay, respectively after $12 \mathrm{~h}$ treatment with FICZ(300nM) or Sema4D(10ng/ml). (D-F) Protein, enzymatic activity and mRNA levels of CYP1A1 were analyzed using Western blot, qPCR and EROD assay, respectively after $12 \mathrm{~h}$ treatment with Sema4D(10ng/ml) or $\mathrm{CH} 233191(30 \mu \mathrm{M})$. (G) EL-4 cells were transfected with the XRE-Luc construct and then subjected to indicated treatments for $12 \mathrm{~h}$. Sema4D-induced XRE promoter activity was assayed by luciferase activity. The data were presented as means \pm S.E.M. The results are representative of three independent experiments, ${ }^{\star *}=p<0.01 ; N . S=$ no significant. 
A

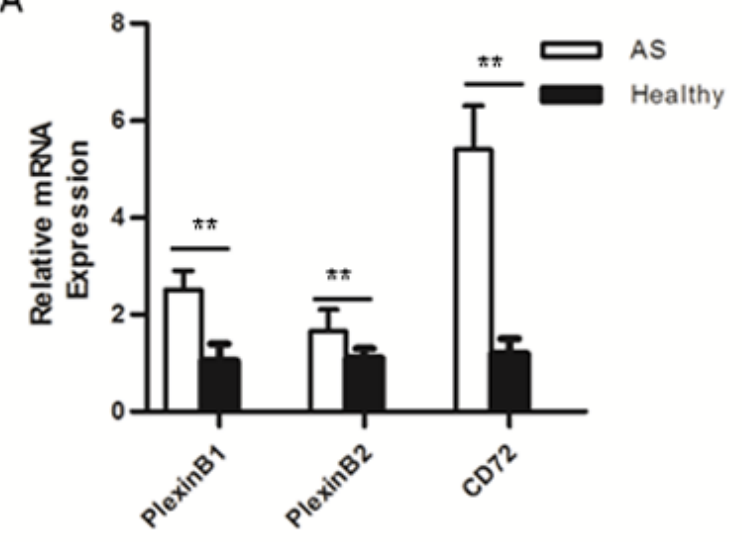

B

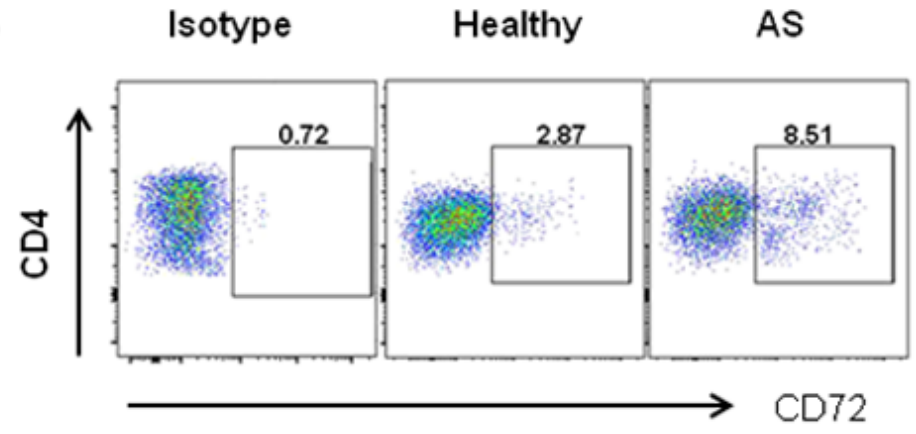

D
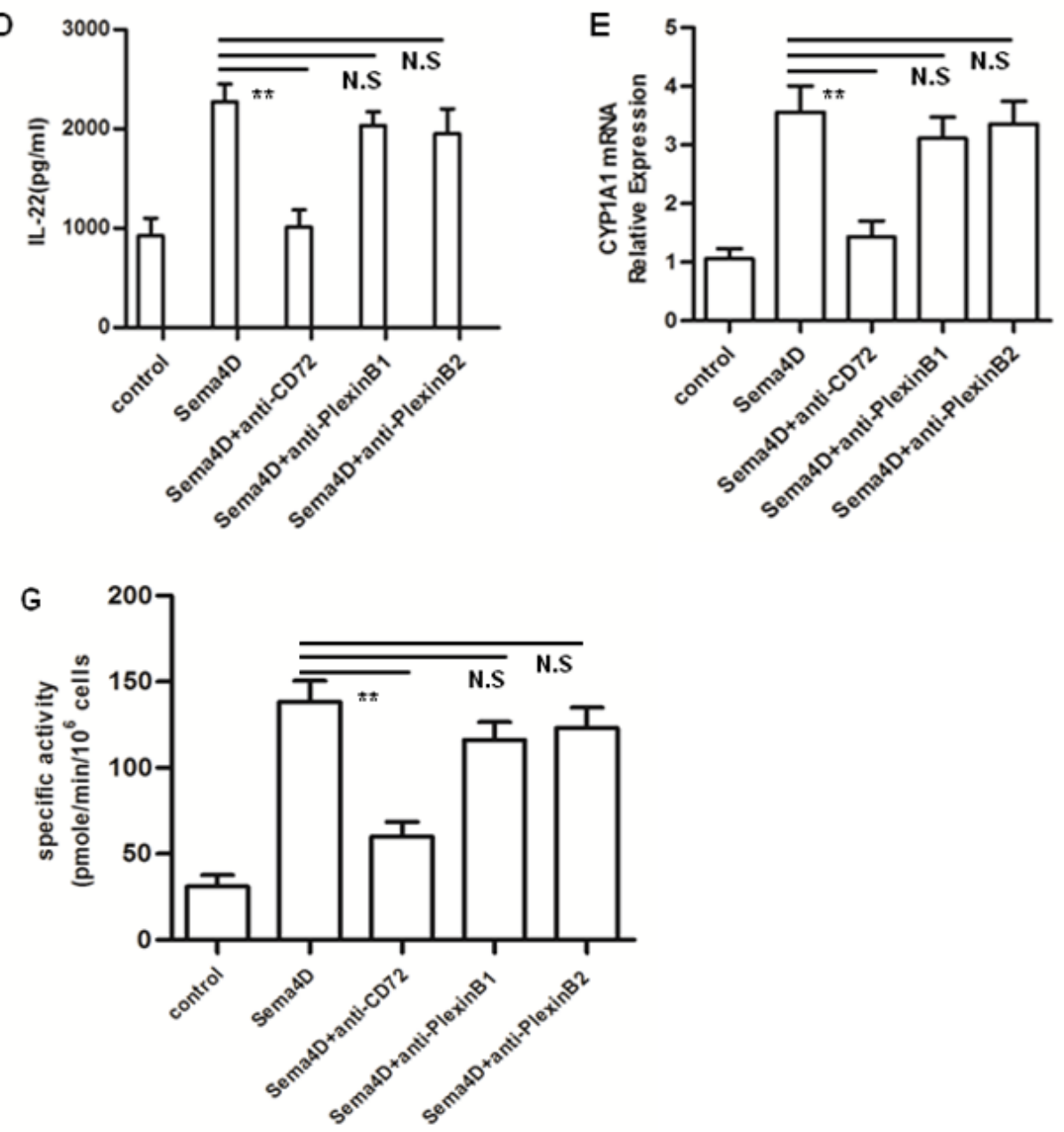

Figure 6

Blocking CD72 ligand abrogates Sema4D-induced cytokine production and AhR activation. (A) Expression of mRNA for Sema4D receptors (plexin B1, plexin B2 and CD72) in peripheral blood CD4+ cells from AS patients and healthy controls. Results shown are from 20 patients with AS and 15 healthy controls. (B) CD72 expression on CD4+ cells from 20 patients with AS and 15 healthy controls was analyzed by flow cytometry. (C-D) IL-17 and IL-22 was quantified in the supernatant of CD4+ T cells from 
Healthy $(n=15)$ and AS patients $(n=20)$ treated with anti-plexin B1, plexin B2 or CD72 antibody, respectively $10 \mu \mathrm{g} / \mathrm{ml}$, in the presence of soluble Sema4D $(10 \mathrm{ng} / \mathrm{ml})$ by ELISA. (E) Expression of mRNA for CYP1A1 in peripheral blood CD4+ cells from 20 patients with AS and 15 healthy controls treated with anti-plexin B1 $(10 \mu \mathrm{g} / \mathrm{ml})$, plexin $\mathrm{B} 2(10 \mu \mathrm{g} / \mathrm{ml})$ or $\mathrm{CD} 72(10 \mu \mathrm{g} / \mathrm{ml})$ antibody in the presence of soluble Sema4D (10ng/ml). (F-G) EL-4 cells were treated with anti-CD3/CD28, anti-plexin B1 $(10 \mu \mathrm{g} / \mathrm{ml})$, plexin $\mathrm{B} 2(10 \mu \mathrm{g} / \mathrm{ml})$ or CD72 $(10 \mu \mathrm{g} / \mathrm{ml})$ antibody in the presence of soluble Sema $4 D(10 \mathrm{ng} / \mathrm{ml})$ for indicated times. After $48 \mathrm{~h}$, the activity of XRE-driven luciferase reporter gene and enzymatic activity of CYP1A1 were detected by using luciferase report gene and EROD assay, respectively. The data were presented as means \pm S.E.M. The results are representative of three independent experiments. ${ }^{* *}=p<0.01 ; N . S=n o$ significant.

\section{Supplementary Files}

This is a list of supplementary files associated with this preprint. Click to download.

- table1.docx 